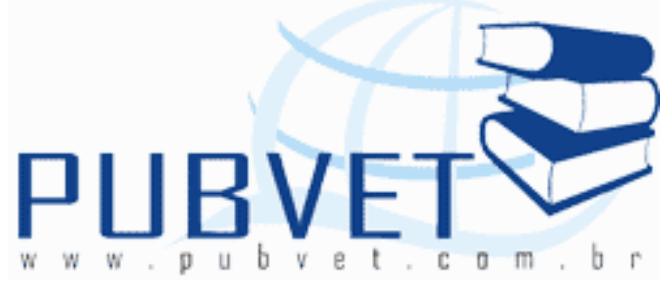

PUBVET, Publicações em Medicina Veterinária e Zootecnia.

\title{
Avaliação na qualidade da carne bovina de abate Halal, comparando-se duas distâncias de transporte ao abatedouro.
}

Vanessa Marques Canella ${ }^{\text {; }}$ Elisa Turchetti ${ }^{\text {II }}$, Luciana Cristina Carrenho Sala ${ }^{\text {III }}$

${ }^{\text {I }}$ Médica veterinária do Grupo Minerva, Supervisora de PPHO, Barretos - SP, Brasil.

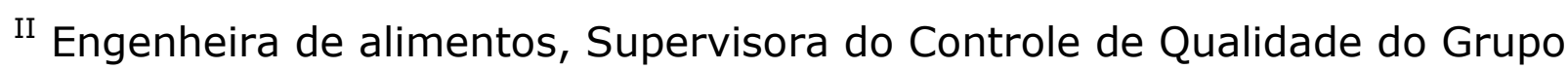
Minerva, Barretos-SP, Brasil.

III Docente de Clínica Médica de Grandes Animais, Centro Universitário Barão de Mauá, Ribeirão Preto - SP, Brasil. e-mail: lucarrenho@gmail.com.

\section{Resumo}

O presente trabalho avaliou o efeito de duas distâncias de transporte rodoviário de bovinos no metabolismo post-mortem, através de análises da curva de pH com o valor inicial e valor final. Foi estabelecida a relação entre as condições de transporte, o jejum e a dieta hídrica, assim como a interferência no aparecimento da carne PSE (Pale, Soft, Exsudative) ou DFD (Dry, Firm, Darky). A carne PSE ocorre devido problemas de estresse no momento do abate, elevando o teor de glicogênio, com uma rápida redução de $\mathrm{pH}$, e que juntamente com a alta temperatura do músculo provocam um estado em que a carne libera água, torna-se flácida e com coloração amena. Enquanto a carne DFD está relacionada com problemas de estresse prolongado sofrido pelo animal antes do abate, acabando com as reservas de glicogênio, impedindo a 
queda do $\mathrm{pH}$, e consequentemente o músculo retém mais água, tornando-se fibroso e mais escuro devido à menor refração da luz e maior ação enzimática, com gasto de oxigênio. O resultado obtido foi a queda do $\mathrm{pH}$, mas sem alteração dos padrões normais de uma carne de qualidade. A coloração permaneceu vermelho-cereja, característico de carne fresca, e o odor era de carne própria para o consumo. Com os resultados obtidos conclui-se que tanto a longa quanto a curta distância não alteraram as propriedades da carne como estrutura, firmeza e textura.

Palavras-chave: transporte rodoviário, curva de pH, PSE e DFD.

\title{
Evaluation of beef meat quality in halal slaughter, comparing two distances of transport to the slaughterhouse
}

\begin{abstract}
The present study evaluated the effect of two distance road transport of cattle post-mortem metabolism through analysis of the $\mathrm{pH}$ curve with the initial value and final value. We established the relationship between the conditions of transport, water fasting and diet, as well as interference in the appearance of meat PSE (Pale, Soft, Exsudative) or DFD (Dry, Firm, Darky). PSE meat occurs due to problems of stress at slaughter, increasing the amount of glycogen, with a rapid reduction of $\mathrm{pH}$, and that coupled with the high temperature causes the muscle in a state that the meat releases water, it becomes flaccid and mild staining. While the DFD meat is associated with problems of prolonged stress experienced by the animal before slaughter, ending the glycogen stores, preventing a decrease in $\mathrm{pH}$, and consequently the muscle holds more water and become fibrous and darker due to the lower refractive light and higher enzymatic activity, with expenditure of oxygen. The result was a decrease in $\mathrm{pH}$, but without changing the normal standards of quality meat. The cherry-red coloration remained characteristic of fresh meat, and the smell of meat was fit for consumption. With these results it is concluded that both
\end{abstract}


the long and the short distance did not change the properties of the meat structure, firmness and texture.

Keywords: road transport, pH curve, PSE and DFD.

\section{INTRODUÇÃO}

Nos últimos anos, o Brasil vem liderando o ranking mundial de exportações de carne bovina, apresentando uma elevação de 3,88\% em termos de receita cambial de janeiro a setembro de 2011. Esse aumento de receita foi impulsionado em grande parte pelo incremento de $30,63 \%$ no preço médio da carne exportada em relação ao mesmo período de 2010 , que subiu para US\$ 5.131 a tonelada. (ABIEC, 2011). As agroindústrias brasileiras com foco no mercado consumidor estrangeiro estão se especializando em realizar o abate religioso, para conquistar povos nos quais a fé rege também os hábitos alimentares. Carnes com o abate diferenciado, conhecido como "HALAL", ganham espaço nas linhas de produção de grandes empresas (FAMBRAS, 2011).

O termo "HALAL" significa permitido para consumo, mas o conceito ultrapassa o simples consentimento, tratando de princípios que vão do respeito a todos os seres vivos até as questões sanitárias. A preocupação com a higiene do alimento estende-se ao bem estar do animal (MAPA, 2011). O mercado "HALAL" em todo o mundo é estimado em mais de US $\$ 400$ bilhões, com crescimento de $15 \%$ ao ano (FAMBRAS, 2011). Atualmente, conceitos como qualidade da carne, carne de qualidade e garantia de qualidade têm ocupado o centro das atenções, tanto nas pesquisas como nas práticas de produção, transformação e comercialização. Não se trata apenas de assegurar o fornecimento de produtos cárneos para a população em quantidade, mas em melhorar as perspectivas de comercialização no mercado em longo prazo, visto que a produção de carne bovina é mais do que suficiente para abastecer o mercado interno (CASTILLO, 2006). 

abate Halal, comparando-se duas distâncias de transporte ao abatedouro. PUBVET, Londrina, V. 6, N. 30, Ed. 217, Art. 1443, 2012.

Devido a isto, os aspectos de qualidade ganham importância cada vez maior, já que somente a "carne de boa qualidade" consegue se destacar nas vendas (CASTILLO, 2006). A qualidade da carne é influenciada por fatores intrínsecos e extrínsecos como prática de manejo, transportes, estresse devido ao tempo de jejum prolongado e aumento de temperatura. Muita ênfase tem sido dada as consequências econômicas do manuseio e transporte deficiente, ao bem-estar pré-abate dos animais e com o uso de métodos humanitários de insensibilização, antes da sangria (CROCETTA, 1996).

O termo estresse é uma expressão genérica, referente a ajustes fisiológicos, tais como alterações no ritmo cardíaco e respiratório, temperatura corporal e pressão sanguínea, que ocorrem durante a exposição do animal às condições adversas. Tais condições ocorrem quando o ambiente torna-se desfavorável para o animal (JUDJE et al. 1989). Com isso a somatória de todos esses fatores relevantes durante o período ante-morte, podem ter um efeito significativo na redução da qualidade da carcaça, conduzindo-a para problemas de carne enegrecida (DFD) seca, firme e escura ou (PSE) pálida, mole e exsudativa (FERNANDEZ et al. 1992; GREGORY, 1994; ROÇA; SERRANO, 1996). Em condições inadequadas, o jejum sempre vem acompanhado de outros fatores estressores e esta associação contribuiria para reduzir a qualidade das carnes, porém segundo JONES et al. (1988), bovinos em jejum ainda podem manter o glicogênio em níveis suficientes para proporcionar acidificação post mortem normal.

Quando se trata de carnes, a amplitude do termo "qualidade" pode levar a diferentes interpretações. Warriss (2000) define qualidade como uma série de componentes como rendimento e composição; aparência e características tecnológicas; palatabilidade; integridade do produto e qualidade ética. $\mathrm{Na}$ indústria de produção de carne bovina o rendimento é fundamental, porém, para o distribuidor, importa apenas saber o tempo que a carcaça ou a carne se mantêm em boa qualidade e própria para consumo. Já o conceito de qualidade para o consumidor abrange aspectos variados, tais como qualidade nutricional, 
CANELLA, V.M., TURCHETTI, E. e SALA, L.C.C. Avaliação na qualidade da carne bovina de abate Halal, comparando-se duas distâncias de transporte ao abatedouro. PUBVET, Londrina, V. 6, N. 30, Ed. 217, Art. 1443, 2012.

qualidade higiênico-sanitária, qualidade do serviço e qualidades sensoriais (SCHUNTZEMBERGER, 2007).

Para produzir uma carne de excelente qualidade é necessário o vínculo do elo de cadeias que incluem pecuaristas, frigoríficos, distribuidores e consumidores. A qualidade do produto determinantemente depende das características de cada elo (COSTA, 2007). As características intrínsecas das carnes, como sua composição química, elevada disponibilidade de água, aminoácidos e pH próximo à neutralidade, são fatores que favorecem o desenvolvimento de uma microbiota extremamente variada. Além disso, ao longo do processamento industrial, inúmeros fatores contribuem, em maior ou menor intensidade, para o aumento e diversificação dessa microbiota contaminante (LEITÃO, 2002).

Admite-se que a carga microbiana do produto final, independente de sua natureza, é resultante da somatória de fatores atuantes nas inúmeras etapas do processo como condições de criação do rebanho; condições de manutenção pré-abate; sangria; remoção da pele e evisceração; lavagem das carcaças; refrigeração, transporte das carcaças; corte e embalagem do produto final (LEITÃO, 1995 apud LEITÃO, 2002).

As condições de abate dos animais, principalmente o estresse antemortem, irão influenciar na reserva de glicogênio nos tecidos, no pH final da carne e na concentração disponível de produtos intermediários do metabolismo, conseqüentemente afetando a natureza dos substratos utilizados pelos microrganismos e aliados a esse fato existem os diferentes gêneros e espécies de microrganismos presentes naturalmente nas carnes que revelam um comportamento variável em relação ao metabolismo e às condições externas da manutenção das carnes. Por conseqüência haverá uma predominância diferente de grupos de microrganismos em função destas condições (LEITÃO, 2002). Por isso a deterioração das carnes é caracterizada pela manifestação de alterações oriundas da atividade microbiana, afetando o aspecto, textura ou o aroma da mesma (LAMBERT et al., 1991 apud LEITÃO, 2002) sendo sua ocorrência dependente de três fatores: o substrato de carne, 
o tipo e número de microrganismos presentes, e, a temperatura (LEITÃO, 2002).

O objetivo do presente estudo incluiu avaliar a influência das diferentes distâncias, condições de transporte, jejum, dieta hídrica e idade no aparecimento da carne PSE (Pale, Soft Eexudative) e carne DFD (Dry, Firm, Darky), levando em consideração os valores de $\mathrm{pH}$ inicial e final. Para tanto foram verificados os valores das curvas de $\mathrm{pH}$ e as características atribuídas à carne destinada ao abate do tipo "HALAL".

\section{MATERIAL E MÉTODOS}

O experimento foi realizado no período de julho a outubro de 2011. Utilizou-se 6 bovinos machos, SRD, pesando entre 350 a $450 \mathrm{~kg}$, com idade de 2 a 3 anos, criados em regime de confinamento, nos municípios de Novo Horizonte - SP e Natalândia - MG, que se localizam a 170 km (curta distância) e 740 km (longa distância), respectivamente, do município de Barretos-SP. O transporte foi realizado por via rodoviária, desde a propriedade de origem até o Frigorífico Minerva S/A.

De cada local de origem foram selecionados três animais de um mesmo lote, todos de carregamentos distintos a fim de obter resultados significativos sobre a influência da distância e stress sobre o pH inicial e final. Esses animais foram desembarcados no frigorífico e submetidos a manejo pré-abate que incluía dieta sólida e dieta hídrica de 12 horas, inspeção ante-mortem, descanso, nova inspeção ante-morte, banho de aspersão, atordoamento e lavagem perianal. $O$ abate foi realizado por um degolador egípcio, mulçumano, conhecedor dos fundamentos do abate de animais no Islã, para realização do abate religioso conhecido como "HALAL". Após o abate, foi feita sangria e os animais foram estimulados eletricamente para que houvesse a remoção do sangue. O processo seguiu com a desarticulação dos membros, retirada da vassoura da cauda, esfola, retirada do órgão genital, oclusão do reto, retirada das orelhas e chifres, remoção das patas, esfola da cabeça, arriação do couro, serragem do peito, retirada do couro, desarticulação e identificação da cabeça, 
oclusão do esôfago, cronologia dentária, separação da cabeça, lavagem da cabeça, evisceração. Depois desse ciclo, as carcaças foram levadas para as câmaras de maturação, onde foram aferidos a temperatura e o pH. Utilizou-se o músculo Longissimus dorsis thoracicus (LD) para as avaliações do pH postmortem, por sua homogeneidade.

As carcaças de curta distância foram identificadas como 191, 192 e 193. E as carcaças de longa distância foram identificadas com 282, 283 e 284. A avaliação do pH foi realizada 60 minutos após o abate sendo considerado o momento 0 (M0) e, a seguir, depois de transcorridas 12 horas, foram feitas novas avaliações de $\mathrm{pH}$ e temperatura (M1). As carcaças permaneceram em câmara de maturação por 24 horas e nova aferição foi realizada nesse momento (M2). No dia seguinte, as carcaças foram encaminhadas para a sala de cortes para que houvesse a separação de partes da carcaça como o quarto dianteiro, traseiro e ponta de agulha, que em seguida seguiram para o procedimento da desossa.

Na desossa é foi feita a separação do músculo sartório (coxão mole) e trapézio torácico (contra filé). De cada quarto traseiro foram retiradas duas porções, sendo uma peça de coxão mole (músculo sartório) e uma de contra file (músculo trapézio torácico). As peças foram colocadas em mesas de inox e novamente foi aferida a temperatura e o pH de cada peça inteira. No final, cada peça inteira foi fatiada em quatro pedaços e o pH desses pedaços também foram aferidos. Após esse processo, as peças foram embaladas a vácuo, encaixotadas e armazenadas em câmara com temperatura entre 0 a $4^{\circ} \mathrm{C}$. O tempo de vida útil em prateleira (shelf life) foi realizado mensalmente, onde foram observados coloração, liberação de exsudato, odor e aferidos temperatura e $\mathrm{pH}$. Depois as peças avaliadas foram descartadas.

\section{RESULTADOS E DISCUSSÃO}

Todo músculo do animal após o abate passa pelo rigor mortis para se transformar em carne. Conforme as condições de estresse que o animal 

abate Halal, comparando-se duas distâncias de transporte ao abatedouro. PUBVET, Londrina, V. 6, N. 30, Ed. 217, Art. 1443, 2012.

encontra-se antes do abate, refletirá na qualidade final da carne devido exclusivamente ao $\mathrm{pH}$ final atingido.

Alguns agentes de estresse, como transporte, jejum prolongado, condições climáticas severas e o comportamento sexual dos machos inteiros, podem resultar em rigor mortis atípico, com grandes prejuízos da qualidade da carne (GONÇALVES et al; 2008).

Houve diferença significativa nos valores de $\mathrm{pH}$, nas primeiras 24 horas do post mortem. As diferenças de $\mathrm{pH}$, em relação ao fator tempo, no transcorrer das reações post mortem, mostram diferentes velocidades metabólicas. A menor distância de transporte $(170 \mathrm{~km})$, no momento 0 apresentou maior $\mathrm{pH}$ comparativamente à maior distância $(740 \mathrm{~km})$. Esse resultado indica uma menor velocidade inicial da glicólise anaeróbica muscular, na menor distância.

De acordo com as Normas da União Européia 2007, o valor de pH após a maturação e antes da desossa, medida em todas as meias carcaças no centro do músculo Longissimus dorsi (entre a $11^{\mathrm{a}}$ e $12^{\mathrm{a}}$ costela), deve ser inferior ou igual a 5,9. Considerando essa norma, temos a incidência de $\mathrm{pH}$ de 7,06 para os grupos de curta distância e de 7,04 para longa distância mostrada pelas Tabelas 1 e 2, e Gráficos 1 e 2.

Tabela 1 - Média do pH post-mortem de bovinos, do grupo de $170 \mathrm{Km}$ (curta distância).

\begin{tabular}{lccc}
\hline $\mathbf{N}^{\circ}$ da Carcaça & M0 & M1 & M2 \\
\hline 191 & 6,81 & 6,58 & 5,75 \\
192 & 6,75 & 6,54 & 5,6 \\
193 & 7,06 & 6,53 & 5,6 \\
Média & 6,84 & 6,55 & 5,64 \\
\hline
\end{tabular}


CANELLA, V.M., TURCHETTI, E. e SALA, L.C.C. Avaliação na qualidade da carne bovina de abate Halal, comparando-se duas distâncias de transporte ao abatedouro. PUBVET, Londrina, V. 6, N. 30, Ed. 217, Art. 1443, 2012.

\section{Gráfico 1 - Curva de pH em relação à curta distância $(170$ km).}

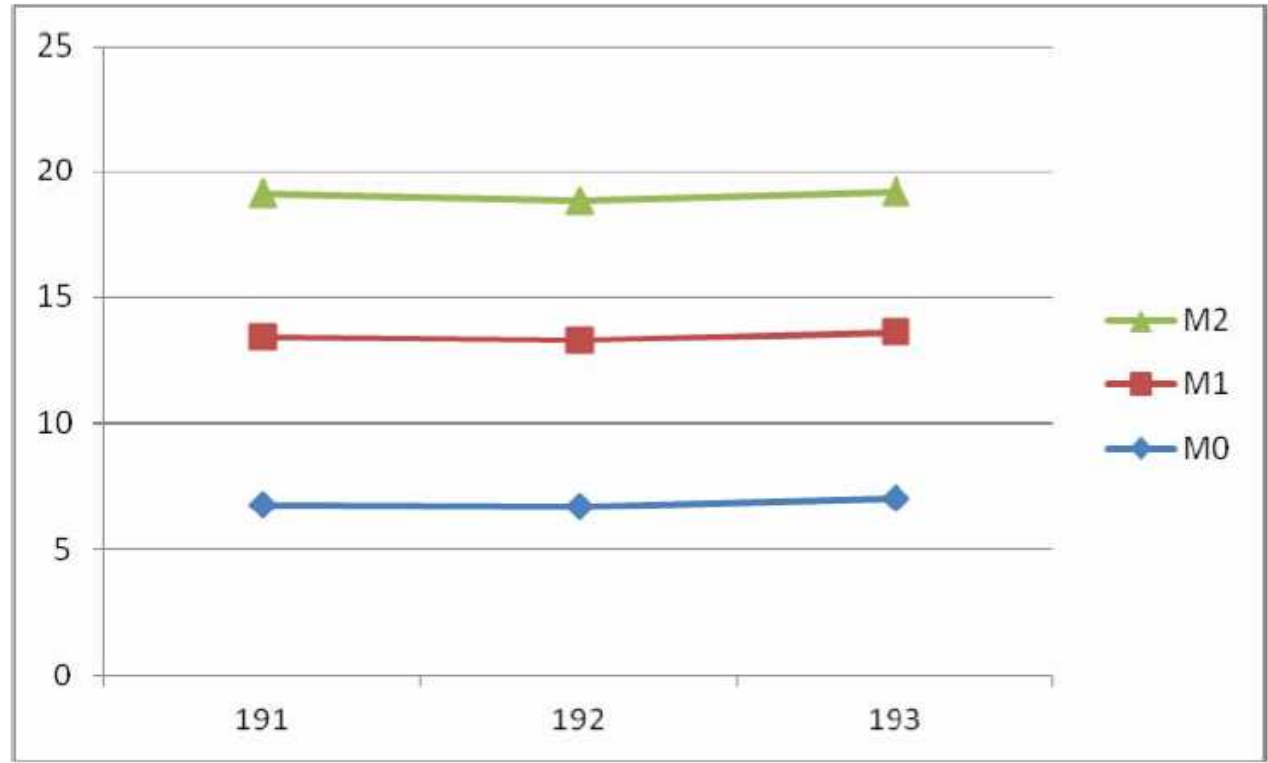

Tabela 2 - Médias do pH post-mortem de bovinos, do grupo de $740 \mathrm{Km}$

\begin{tabular}{lccc}
\hline $\mathbf{N}^{\circ}$ da Carcaça & M0 & M1 & M2 \\
\hline $\mathbf{2 8 2}$ & 7,04 & 6,25 & 5,74 \\
$\mathbf{2 8 3}$ & 6,76 & 6,43 & 5,76 \\
$\mathbf{2 8 4}$ & 6,74 & 6,49 & 5,9 \\
Média & 6,85 & 6,39 & 5,8 \\
\hline
\end{tabular}


CANELLA, V.M., TURCHETTI, E. e SALA, L.C.C. Avaliação na qualidade da carne bovina de abate Halal, comparando-se duas distâncias de transporte ao abatedouro. PUBVET, Londrina, V. 6, N. 30, Ed. 217, Art. 1443, 2012.

Gráfico 2 - Curva de pH em relação a longa distância (740 km).

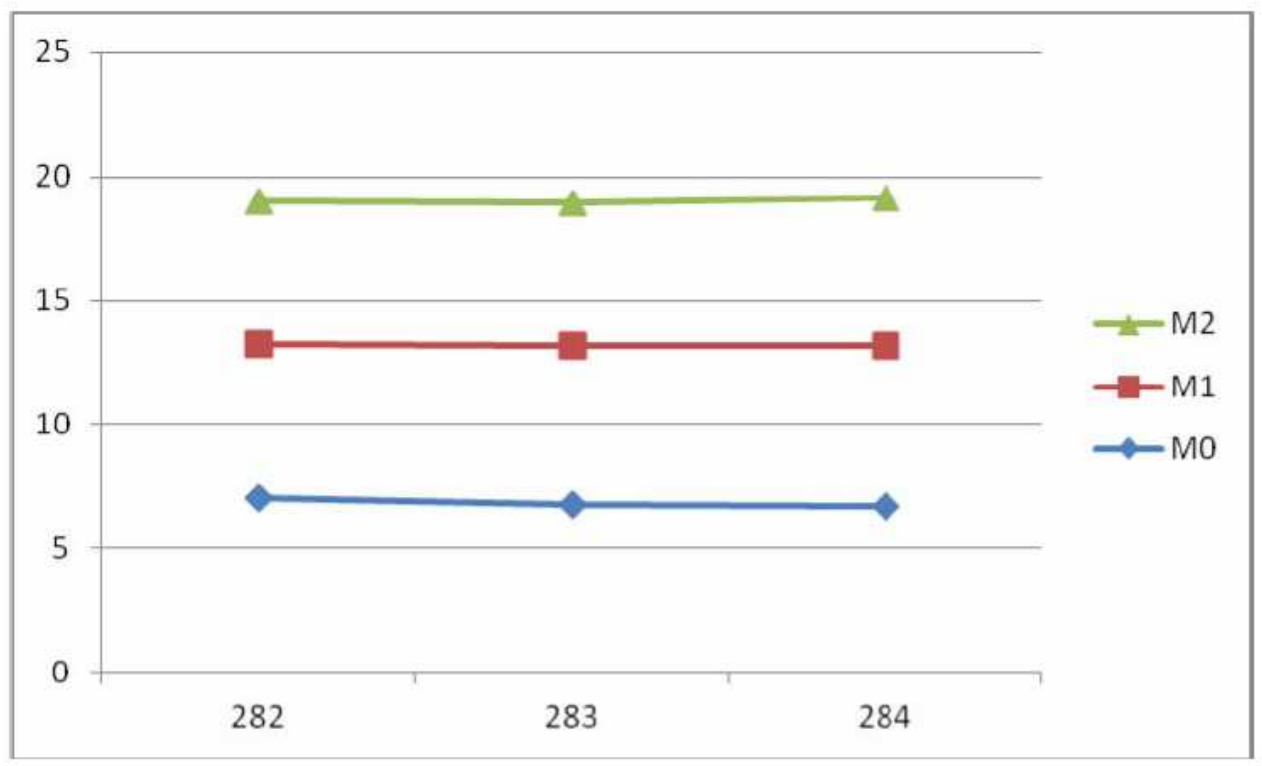

Após 24 horas de maturação os quartos traseiros foram desossados e as três peças de contra filé e três peças de coxão mole foram divididas em três peças, totalizando nove peças de Contra-Filé e nove peças de Coxão Mole. Houve uma nova aferição de pH para cada peça. As Tabelas 3 e 4 e gráfico 3 e 4, mostram os valores de $\mathrm{pH}$ das peças de Contra filé e Coxão mole de curta distância .

Tabela 3 - RELAÇÃO DOS MESES DAS ANÁLISES COM CARCAÇAS DE CURTA DISTÂNCIA

\begin{tabular}{lcccccc}
\hline \multicolumn{7}{c}{ Contra Filé } \\
\hline & $\begin{array}{c}\text { Julho } \\
(\mathbf{1})\end{array}$ & $\begin{array}{c}\text { Julho } \\
(\mathbf{2})\end{array}$ & Julho (3) & Agosto (1) & Setembro (2) & Outubro (3) \\
\hline 191 & 6,65 & 5,63 & 5,65 & 5,67 & 5,79 & 5,58 \\
\hline 192 & 5,59 & 5,57 & 5,71 & 5,62 & 5,74 & 5,54 \\
\hline 193 & 5,66 & 5,72 & 5,73 & 5,64 & 5,75 & 5,57 \\
\hline Média & 5,97 & 5,64 & 5,70 & 5,64 & 5,76 & 5,56 \\
\hline
\end{tabular}


CANELLA, V.M., TURCHETTI, E. e SALA, L.C.C. Avaliação na qualidade da carne bovina de abate Halal, comparando-se duas distâncias de transporte ao abatedouro. PUBVET, Londrina, V. 6, N. 30, Ed. 217, Art. 1443, 2012.

Gráfico 3 - Curva de pH em relação a longa distância $(740$ km).

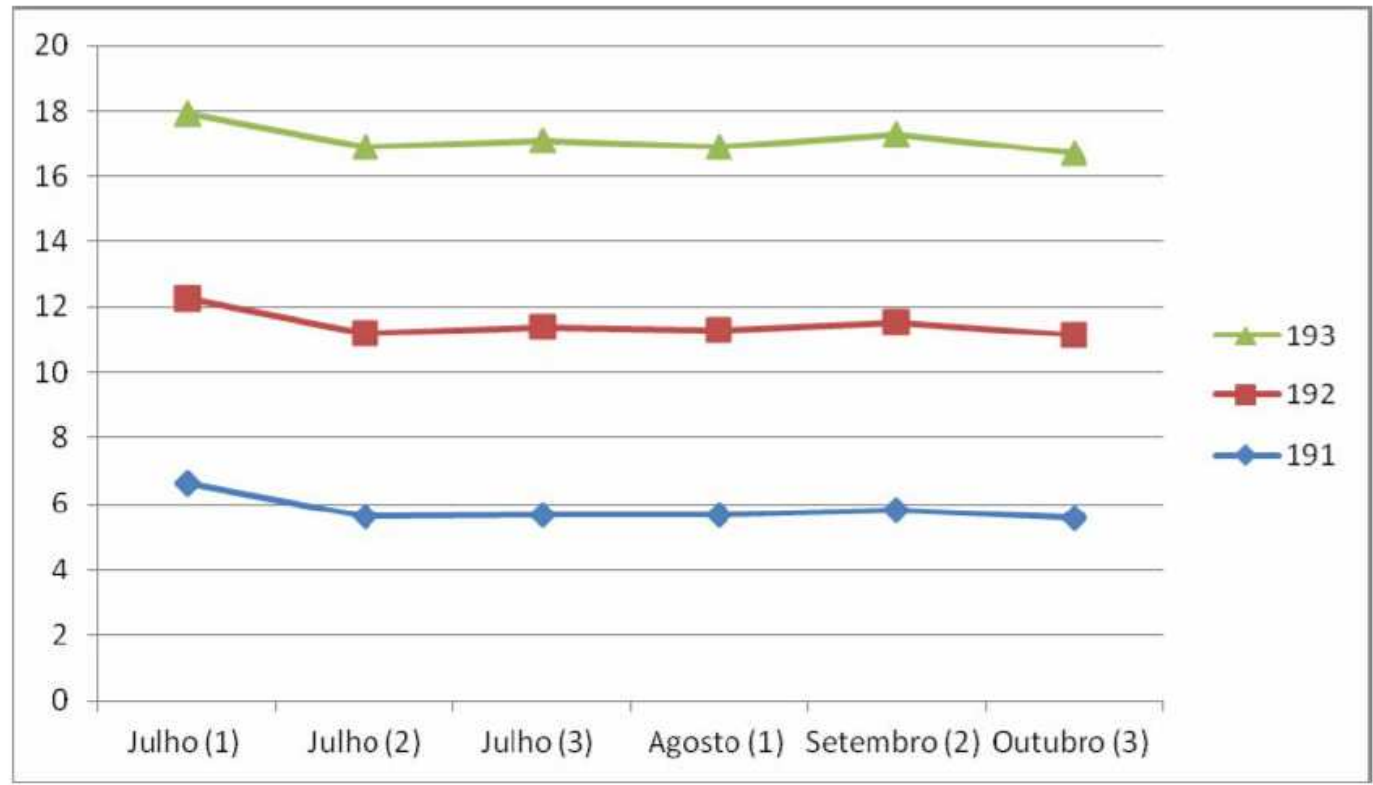

Tabela 4 - RELAÇÃO DOS MESES DAS ANÁLISES COM CARCAÇAS DE CURTA DISTÂNCIA

Coxão Mole Curta Distância

\begin{tabular}{lcccccc}
\hline & Julho (1) & Julho (2) & Julho (3) & Agosto (1) & Setembro (2) & Outubro (3) \\
\hline 191 & 5,57 & 5,68 & 5,67 & 5,72 & 5,67 & 5,34 \\
192 & 5,63 & 5,58 & 5,59 & 5,64 & 5,67 & 5,1 \\
193 & 5,58 & 5,59 & 5,62 & 5,68 & 5,66 & 5,45 \\
\hline
\end{tabular}


CANELLA, V.M., TURCHETTI, E. e SALA, L.C.C. Avaliação na qualidade da carne bovina de abate Halal, comparando-se duas distâncias de transporte ao abatedouro. PUBVET, Londrina, V. 6, N. 30, Ed. 217, Art. 1443, 2012.

Gráfico 4 - Curva de pH em relação a curta distância (170 km).

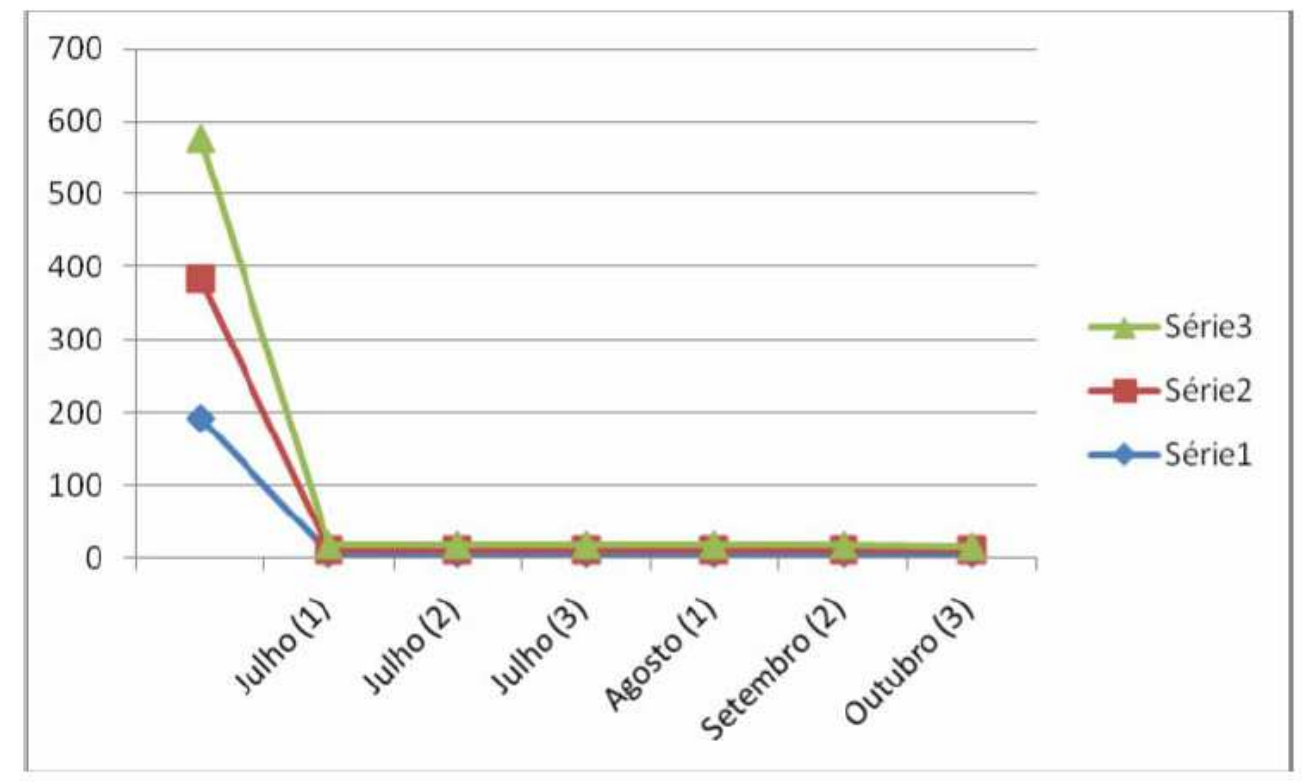

Dez dias após a desossa da curta distância foi realizada a desossa das peças de longa distância. As três peças de Contra filé e três peças de Coxão mole foram divididas em três peças cada totalizando nove peças de Contra File e nove peças de Coxão Mole. Houve uma nova medição de pH para cada peça mostrados nas Tabelas 5 e 6 e nos gráficos 5 e 6 .

\section{Tabela 5 - RELAÇÃO DOS MESES DAS ANÁLISES COM CARCAÇAS DE LONGA DISTÂNCIA}

Contra Filé Longa Distância

\begin{tabular}{ccccccc}
\hline & Julho (1) & Julho (2) & Julho (3) & Agosto (1) & Setembro (2) & Outubro (3) \\
\hline $\mathbf{2 8 2}$ & 5,73 & 5,58 & 5,57 & 5,8 & 5,74 & 5,58 \\
$\mathbf{2 8 3}$ & 5,6 & 5,57 & 5,54 & 5,61 & 5,66 & 5,65 \\
\hline & 5,53 & 5,55 & 5,51 & 5,67 & 5,6 & 5,42 \\
\hline
\end{tabular}


CANELLA, V.M., TURCHETTI, E. e SALA, L.C.C. Avaliação na qualidade da carne bovina de abate Halal, comparando-se duas distâncias de transporte ao abatedouro. PUBVET, Londrina, V. 6, N. 30, Ed. 217, Art. 1443, 2012.

\section{Gráfico 5 - Curva de pH em relação a longa distância $(740$ km).}

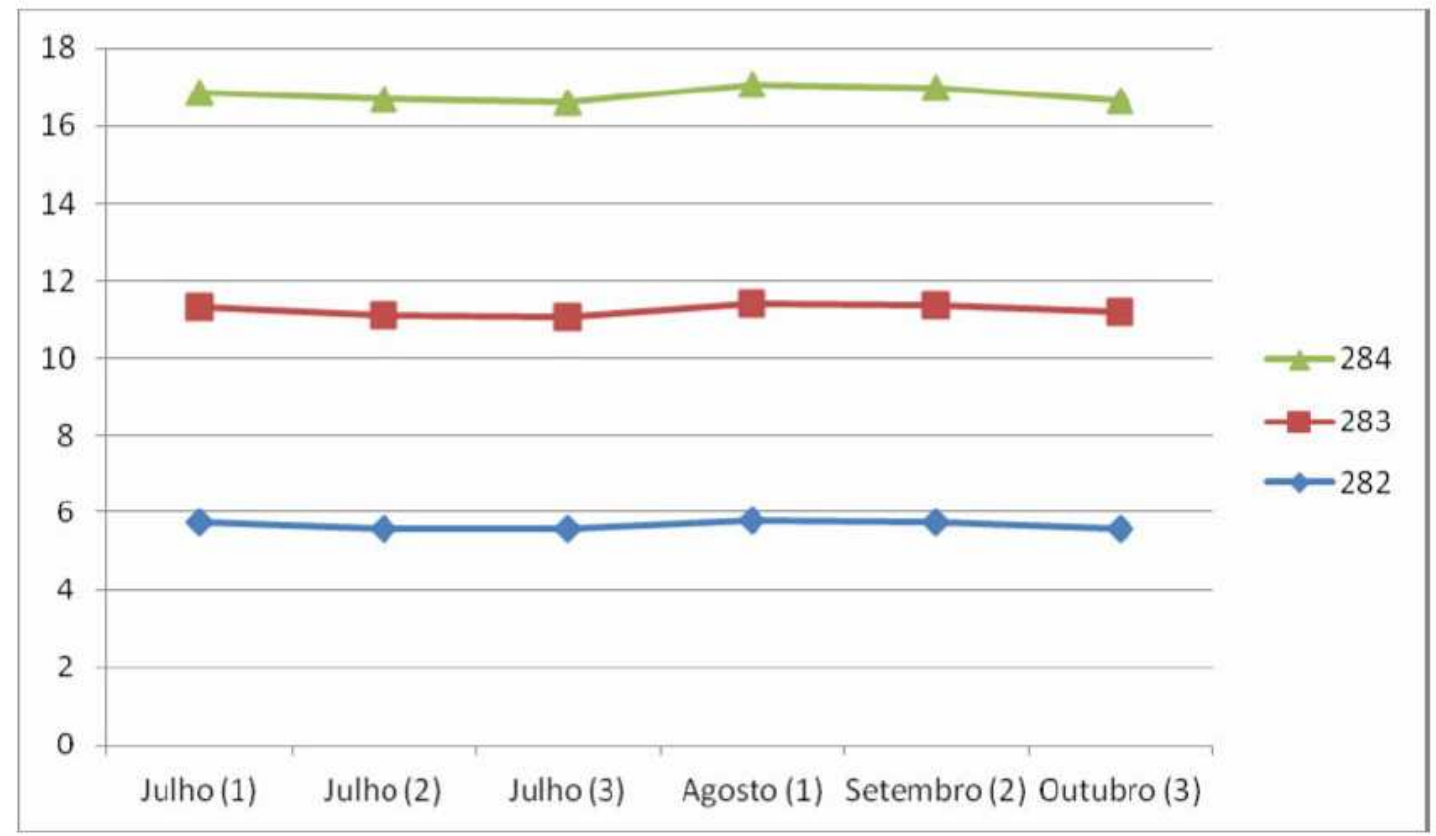

Tabela 6 - RELAÇÃO DOS MESES DAS ANÁLISES COM CARCAÇAS DE LONGA DISTÂNCIA

Coxão Mole Longa Distância

\begin{tabular}{lcccccc}
\hline & Julho (1) & Julho (2) & Julho (3) & Agosto (1) & Setembro (2) & Outubro (3) \\
\hline $\mathbf{2 8 2}$ & 5,67 & 5,64 & 5,63 & 5,76 & 5,63 & 5,32 \\
\hline $\mathbf{2 8 3}$ & 5,54 & 5,58 & 5,63 & 5,71 & 5,59 & 5,52 \\
\hline \multirow{2}{*}{ Média } & 5,62 & 5,49 & 5,61 & 5,77 & 5,58 & 5,2 \\
\hline
\end{tabular}




\section{Gráfico 6 - Curva de pH em relação a longa distância $(740$ km).}

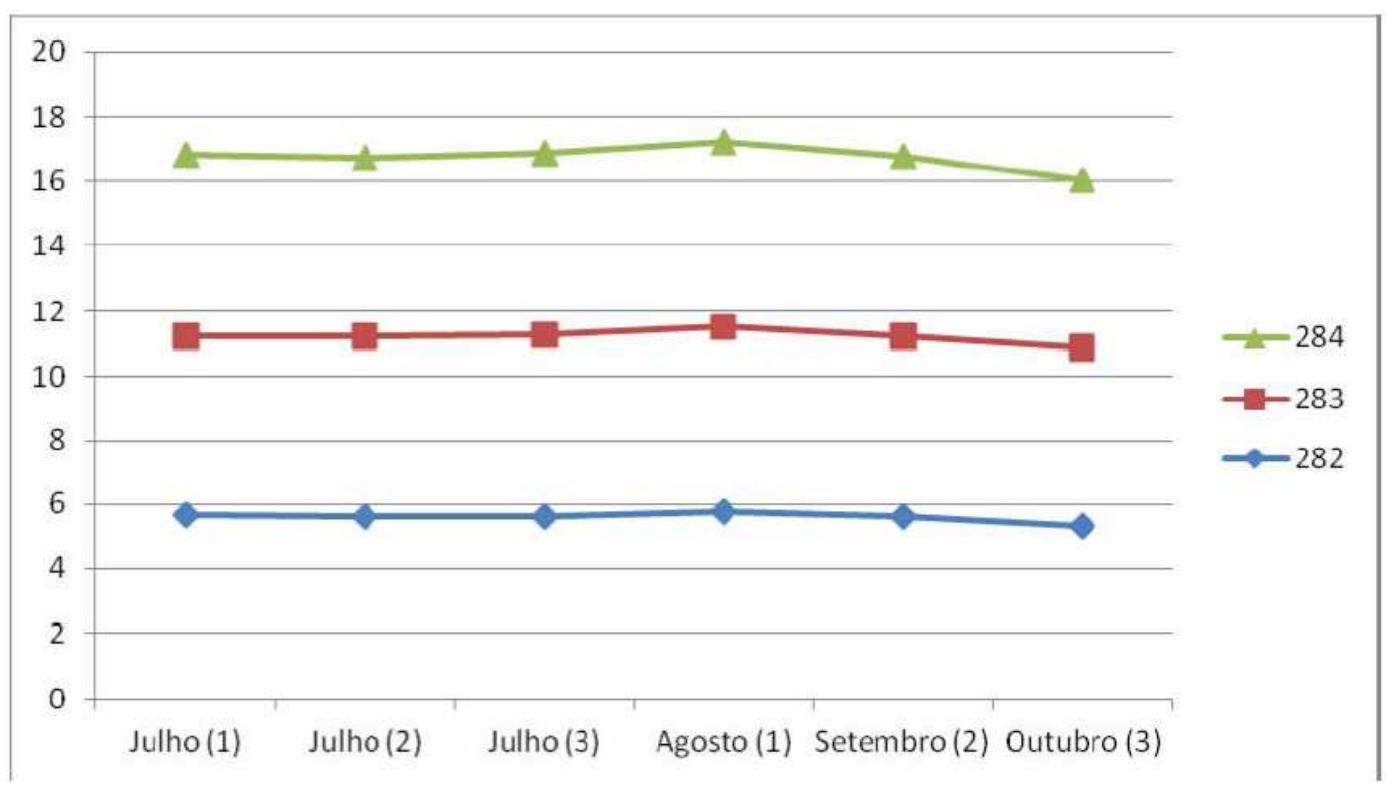

Para realizar o "Self Life" foi estipulada à abertura das caixas de curta e longa distância em diferentes datas do início da pesquisa. Conforme os resultados das amostras avaliadas, todas atenderam as normas da União Européia com valor de $\mathrm{pH}$ inferior ou igual a 5,9. Notam-se pequenas oscilações de valores de $\mathrm{pH}$ final, porém nada que alterasse suas características organolépticas como coloração, sabor, aroma e integridade da carne, não apresentando riscos a saúde publica e nem a perda de seu valor de mercado, como cita (ICMSF, 1980, apud LEITÃO, 2002) que preconizam os parâmetros de avaliação sanitária tendo em vista uma associação nítida com o aspecto de saúde pública.

Sobre alterações da carne como PSE que atualmente tem grande importância na indústria de carnes suína, por serem animais mais susceptíveis ao estresse em relação aos bovinos, tem causas com fatores pré-abate, genética, nutrição e manejo (CALAU 2002). Devido a esses fatores ocorre à decomposição acelerada do glicogênio após o abate, que causa um valor de pH 
muscular baixo, geralmente inferior a 5,8, enquanto a temperatura do músculo ainda esta próxima do estado fisiológico $\left(>38^{\circ} \mathrm{C}\right)$, acarretando um processo de desnaturação protéica comprometendo as propriedades funcionais da carne (D'SOUZA, 1998). Já a carne DFD que também está relacionado com o manejo pré-abate, exercícios físicos, transporte, movimentação, o jejum prolongado e o contato com outros machos estranhos ao seu ambiente acarretam o consumo das reservas de glicogênio, levando à lentidão da glicólise com relativa diminuição da formação de ácido lático muscular. $\mathrm{O} \mathrm{pH}$ reduz ligeiramente nas primeiras horas e depois se estabiliza, permanecendo em geral em níveis superiores a 6,0 (LENGERKEN, 2002).

O período de descanso ou dieta hídrica no matadouro é o tempo necessário para que os animais se recuperem totalmente das perturbações surgidas pelo deslocamento desde o local de origem até ao estabelecimento de abate. De acordo com o artigo no. 110 do RIISPOA/Regulamento de Inspeção Industrial e Sanitária de Produtos de Origem Animal, os animais devem permanecer em descanso, jejum e dieta hídrica nos currais por 24 horas, podendo este período ser reduzidos em função de menor distância percorrida (JOAQUIM, 2002). Em relação aos resultados obtidos com ausência de alterações como PSE e DFD, pôde-se afirmar que é devido ao pequeno número de amostras utilizadas, horas de descanso adequadas de acordo com as distâncias percorridas, uma dieta hídrica e dieta sólida oferecidas devido ao tempo que esses animais permaneceram nos currais de descanso e um manejo pré abate adequado, evitando assim alterações nos produtos finais. Resultados esses diferentes encontrados pelo (BATISTA DE DEUS, 1999) que houve uma diferença significativa no $\mathrm{pH}$ em função da distância de transportes dos animais.

\section{CONCLUSÕES}

O transporte rodoviário e o manejo inadequado dos animais nas fazendas mostram-se importantes causas de perdas econômicas devido ao parâmetro de $\mathrm{pH}$ influenciando na qualidade da carne. Contudo, os resultados obtidos no 
CANELLA, V.M., TURCHETTI, E. e SALA, L.C.C. Avaliação na qualidade da carne bovina de abate Halal, comparando-se duas distâncias de transporte ao abatedouro. PUBVET, Londrina, V. 6, N. 30, Ed. 217, Art. 1443, 2012.

presente trabalho não oferecem condições para estabelecer se há tendências em diminuir ou aumentar a ocorrência da incidência de carnes PSE e DFD nos rebanhos bovinos, devido às inúmeras variáveis que conduzem à sua formação e a pequena quantidade de amostras. Entretanto esse estudo revela a necessidade premente de se realizar um acompanhamento sistemático na cadeia produtiva desses animais com a finalidade de obter um padrão de manejo para que com esse diagnóstico, e dessa forma, implantar um controle nos processos para obtenção das carnes bovinas evitando prejuízos econômicos Nas condições do presente estudo, pôde-se concluir que através dos valores médios de $\mathrm{pH}$, não obtiveram nenhum tipo de alteração como DFD e PSE nos produtos finais.

\section{REFERÊNCIAS}

ABIEC. Associação Brasileira das Indústrias Exportadoras de Carne. Exportação de carne bovina cresce $\mathbf{3 , 8 \%}$ no ano. [2011]. Disponível em: http://souagro.com.br/abiec-receitacom-exportaçao-de-carne-bovina-cresce- 38-no-ano. Acessado em 09 de outubro de 2011.

BATISTA DE DEUS. Efeito da distância de transporte de bovinos no metabolismo post mortem. Dissertação (mestrado em Medicina veterinária) UFPEL/FAEM, 1999.

CULAU, P. O. V.; LÓPEZ, J.; RUBENSAM, J. M.; LOPES, R. F. F.; NICOLAIEWSKY, S. Influência do gene halotano sobre a qualidade da carne. R. Bras. Zoot., v. 31, n. 2, p. 954-961, 2002.

CASTILHO, C.J.C. (Editora). Qualidade da Carne. São Paulo: Livraria Varela, 2006.

COSTA. A.B.T.Qualidade em alimentos. Brasília - DF, 2007. Trabalho de Conclusão de curso, 2007

CROCETTA, I. Abate humanitário. Revista Nacional da Carne, n. 227, p. 56- 60, 1996.

D'SOUZA, D. N.; DUNSHEA, F. R.; WARNER, R. D.; LEURY, B.J. The effect of handling preslaughter and carcass processing rate post-slaughter on pork quality. Meat Sci., v. 50, $\mathrm{n}$. 4, p. 429-437, 1998.

FERNANDEZ, X., MAGARD, M. \& TORNBERG, E. The variations in pig muscle glycolitic potential during lairage - an in vivo study. Meat Science, v. 32, p.81-91, 1992.

GONÇALVES, P. B. D.; FIGUEIREDO, J. R.; FREITAS, V. J.;Biotécnicas aplicadas à reprodução animal. São Paulo: Roca, 2008.

ICMSF International Commission on Microbiological Specification for Foods. Microbial ecology of foods. Volume 1, Factors affecting life and death of microorganisms. Orlando: Academic Pr. p. $311,1980$.

JOAQUIM, C.F.; Tese: Efeitos da distância de transporte em parâmetros post mortem de carcaça bovina. Universidade Estadual Paulista. Faculdade de Medicina Veterinária e Zootecnia. Botucatu. São Paulo, 2002. 
JONES, S.D.M., SCHAEFER, A.L., TONG, A.K.W. \& VICENT, B.C. The effects of fasting and transportation on beef cattle. II body component change, carcass composition and meat quality. Livest. Product. Sci., v. 20, p. 23-25, 1988.

JUDGE, M., ABERLE, E., FORREST, J. Principles of meat science. Iowa : Kendal Hunt Publication, 1989.

LAMBERT, A. D., SMITH, J. P., DODDS, K. I. Shelf Life Extension and Microbiological Safety of Fresh Meat. Food Microbiology, Londres, v.8, p.267-297, 1991.

LEITÃO, M.F.F. Aspectos microbiológicos das carnes In: CONTRERAS, C.J. et al. Higiene e Sanitização da Indústria de Carnes e Derivados. São Paulo: Varela, 2002.

LEITÃO, M.F.F. Controle do desenvolvimento microbiano no processamento industrial da carne e produtos. B.ITAL. Campinas, v.21, p. 89-108, 1995.

LENGERKEN, G.; MAAK, S.; WICKE, M. Muscle metabolism and meat quality of pigs and poultry. Veterinrija Ir Zootechinika, v. 42, p. 82-86, 2002.

SCHUNTZEMBERGER. A.M.S. A qualidade da carne bovina e sua influência na formação de preços para o mercado interno. Curitiba, 2007. Monografia (Graduação em Medicina Veterinária)- Universidade Federal do Paraná, 2007.

WARRIS, P. D. 2000. In: Meat Science: an introductory text. Warris, P. D. (ed), CABI Publishing Company (Oxon), 2000. 